
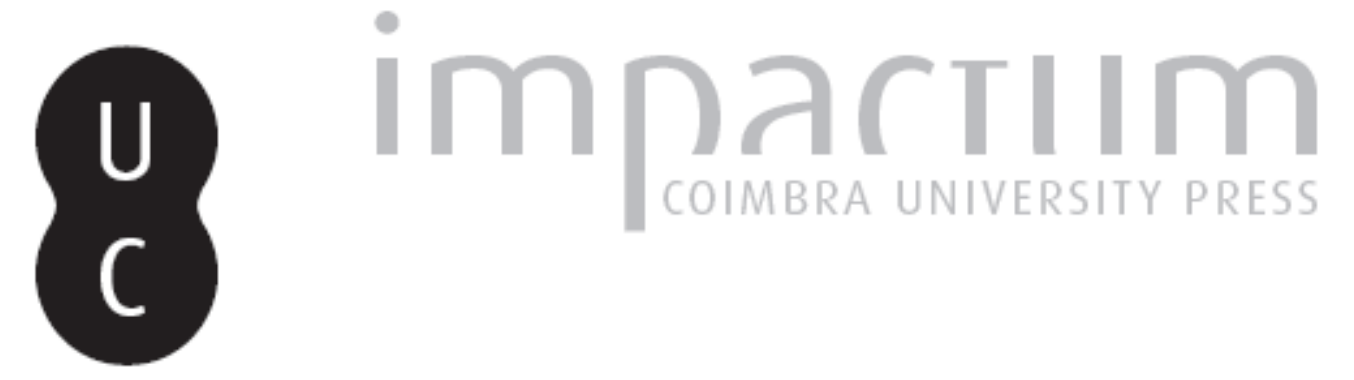

\title{
Revisitar a Odisseia e repensar Ulisses
}

Autor(es): $\quad$ Gersão, Teolinda

Publicado por: Imprensa da Universidade de Coimbra

URL persistente:

URI:http://hdl.handle.net/10316.2/33997

DOI:

DOI:http://dx.doi.org/10.14195/0872-2110_58_1

Accessed : $\quad$ 26-Apr-2023 11:37:26

A navegação consulta e descarregamento dos títulos inseridos nas Bibliotecas Digitais UC Digitalis, UC Pombalina e UC Impactum, pressupõem a aceitação plena e sem reservas dos Termos e Condições de Uso destas Bibliotecas Digitais, disponíveis em https://digitalis.uc.pt/pt-pt/termos.

Conforme exposto nos referidos Termos e Condições de Uso, o descarregamento de títulos de acesso restrito requer uma licença válida de autorização devendo o utilizador aceder ao(s) documento(s) a partir de um endereço de IP da instituição detentora da supramencionada licença.

Ao utilizador é apenas permitido o descarregamento para uso pessoal, pelo que o emprego do(s) título(s) descarregado(s) para outro fim, designadamente comercial, carece de autorização do respetivo autor ou editor da obra.

Na medida em que todas as obras da UC Digitalis se encontram protegidas pelo Código do Direito de Autor e Direitos Conexos e demais legislação aplicável, toda a cópia, parcial ou total, deste documento, nos casos em que é legalmente admitida, deverá conter ou fazer-se acompanhar por este aviso.

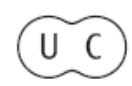


COIMBRA • 2013
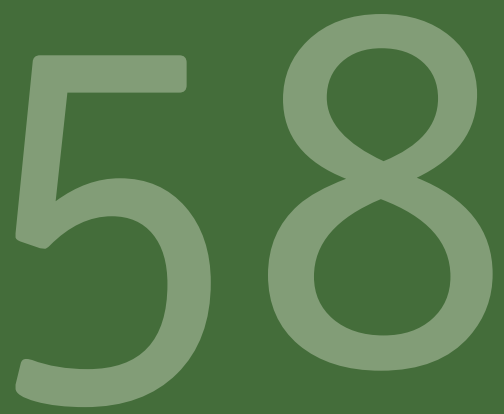

BOLETIM DE

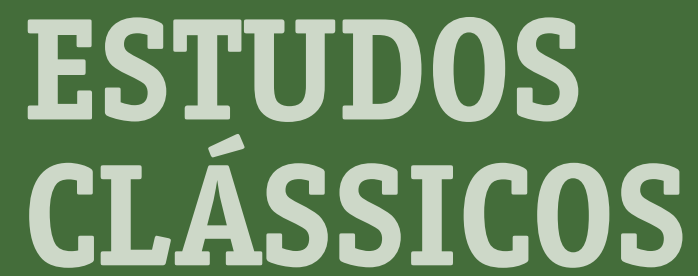

\author{
ASSOCIAÇÃO \\ PORTUGUESA \\ DE ESTUDOS \\ CLÁSSICOS \\ INSTITUTO \\ DE ESTUDOS \\ CLÁSSICOS
}




\title{
REVISITAR A ODISSEIA E REPENSAR ULISSES
}

\author{
TEOLINDA GERSÃ0
}

A Odisseia, que sempre li como o primeiro romance europeu, matriz de todos os outros, tem-me acompanhado ao longo da vida. Será sobre o mito de Ulisses que irei aqui tecer algumas considerações, relacionando-as com o meu romance A Cidade de Ulisses ${ }^{1}$, num breve texto que não pretende ter um olhar especializado nem erudito sobre a cultura clássica e estará certamente fora do contexto deste Boletim. Mas talvez seja esse afinal o papel dos escritores e da literatura: sair sempre de todos os contextos.

Num excelente artigo², Rogério Puga refere os principais autores, clássicos e modernos, que referem a ligação de Ulisses a Lisboa, não só em Portugal como noutras línguas. Muitos deles, da Antiguidade e contemporâneos, eram do meu conhecimento, (como por exemplo os brilhantes ensaios sobre o tema de Raúl Miguel Rosado Fernandes ou Aires Nascimento). De passagem, referi algumas fontes no romance Estrabão, Solino, Santo Isidoro etc., até aos nossos renascentistas. Igualmente li, por interesse pessoal, ao longo de décadas, alguma da imensa bibliografia sobre Lisboa. No entanto uma das minhas preocupações ao escrever o romance foi manter a focalização estritamente centrada na visão das personagens, pondo de lado tudo o que pudesse excedê-la. As personagens que, não inocentemente, defini como artistas plásti-

1 Teolinda Gersão, A Cidade de Ulisses, Lisboa, Sextante Editora, 2011.

2 Rogério Miguel Puga, "Ut pictura poiesis: O mito da fundação de Lisboa por Ulisses em A Cidade de Ulisses de Teolinda Gersão”, Ágora 15 (2013), 293-312. 
cos colocam-se numa perspectiva livre e criativa, que evita qualquer erudição (mesmo quando a integra), e se mantém acima de tudo visual, construída a partir de um núcleo reduzido de imagens fortes.

O ponto de partida é o mito da fundação de Lisboa por Ulisses, que conta pelo menos dois mil anos e cuja responsabilidade não nos cabe, enquanto portugueses, mas provém de antigas fontes clássicas, difundidas pelos romanos, a quem interessava prestigiar com a aura da cultura helénica uma cidade importante do seu império.

Nas muitas versões do mito de Ulisses, ao longo dos séculos, a moderna versão de Joyce é incontornável. Por isso as personagens a referem, verificando no entanto que Dublin nada tem a ver com Ulisses, a não ser na vontade e na imaginação joycianas. Em comparação, Lisboa surge em considerável vantagem: independentemente da imaginação ou vontade de quem olha, existe uma tradição milenar que liga a cidade à personagem de Homero. Neste ponto Paulo e Cecília não terão, portanto, de inventar nada, apropriam-se do que já foi inventado e deixam-se conduzir por um imaginário antiquíssimo: um mito que torna Lisboa uma cidade literária ab initio, porque fundada por uma personagem ficcional. Saída de um livro, Lisboa é ela mesma um texto (visual e mental) que convida a ser lido/decifrado. A literatura funde-se com as artes plásticas; palavras, imagens, histórias tornam-se matéria visual de quadros e esculturas - que por outro lado têm, como os livros, uma dimensão conceptual. Estamos em pleno diálogo entre as artes, e vemos construir-se o projecto de uma exposição/instalação que se propõe ver e dar a ver ao visitante uma Lisboa (re)inventada. o que não será uma aventura inócua, porque entrar numa obra de arte implica um risco: o visitante da exposição não será o mesmo que nela entrou, foi transformado pela travessia. Tal como o leitor de um livro não deverá ser o mesmo antes e depois de o ter lido.

É a esta leitura-travessia da cidade que se dedicam, de um modo lúdico, os artistas-amantes, que encaram o seu objectivo com ironia, 
apenas como um "jogo", conscientes da dificuldade ou impossibilidade de olhar/ interpretar/dar a ver uma cidade a que já Herculano atribuía mais de trinta séculos de História.

No entanto, anterior à História e ultrapassando-a pelo seu poder intemporal e simbólico, o mito mantém-se presente e actuante. Nos passos de ambos, através da cidade, são as pegadas míticas de Ulisses que subjazem. Como a personagem de Homero, também Paulo e Cecília estão em busca de si próprios, um do outro, da intimidade, do amor. E acreditam que uma história de amor bem sucedida termina com um regresso a casa.

Como Ulisses, também eles são "ninguém", ou seja, "qualquer um" e "toda a gente", ao mesmo tempo que são eles próprios. Únicos. Se o mito transforma Ulisses em arquétipo do ser humano, em viagem pela vida, qualquer um se pode identificar com ele, sem medo de cair no pecado da hubris. Daí a persistência e a ressurreição do mito, nas várias literaturas, em diferentes épocas, até à actualidade²:

Ulisses é um homem que considera a vida mortal suficientemente atractiva para que não queira trocá-la por nada, nem mesmo pela imortalidade.

É, portanto, uma figura positiva, de afirmação, e a Odisseia é um romance de amor feliz. Ulisses quer voltar, e volta, para casa. Para a mulher amada.

Viajante, navegador, homem de perigos e situações-limite, conquistador de cidades, (decisivo na tomada de Tróia através do estratagema

3 Poderíamos citar, na Antiguidade, Ovídio (Metamorfoses), Séneca (As Troianas), Sófocles (Filoctetes) e, entre os modernos, para além do referido Ulisses de Joyce, ainda, por exemplo, Dante (Inferno), Shakespeare (Troilus and Cressida), Alfred Tennyson (Ulysses), Jean Giono (Naissance de l'odyssée), Jean Giraudoux (La guerre de Troie n'aura pas lieu), Nikos Kazantzakis (Odisseia), Alberto Moravia (O Desprezo), Ezra Pound (Os Cantos), Giorgios Seféris (Poemas), Kaváfis (Poemas, nomeadamente "Ítaca"). 
do cavalo), sabe usar a inteligência e a racionalidade, mas também a intuição e a astúcia; é capaz de recuar e pensar, mas também de rapidamente captar e apreender novas situações a que se adapta.

É também eloquente, tem o dom da palavra, sabe liderar, persuadir e narrar. Desde logo a sua própria história, como faz na corte de Alcínoo, onde, por um golpe de mestre, Homero, que domina com a maior eficácia as artes surpreendentes da narrativa, ainda válidas milénios depois, coloca o aedo Demódoco cantando a história de Ulisses. Ao revelar a sua identidade, Ulisses substitui-se ao aedo e passa a ser o narrador assumindo, ao fazê-lo, o lugar de Homero.

Também neste caso será Paulo o narrador, o que tem o dom da palavra, mesmo que a sua narrativa seja apenas para si próprio, um monólogo que é um diálogo imaginado, portanto impossível, com Cecília, quando ela não está lá para ouvi-lo.

Contar a sua história é conhecer-se, saber quem se é, ter integrado a experiência vivida. 0 momento em que Ulisses narra/assume a sua história - a sua identidade - é o momento em que chega ao fim da errância, e merece voltar a casa. Como acontece com Paulo, quando volta a Lisboa, onde reencontra Cecília.

Ulisses é, aliás, o único que volta. Os seus companheiros estão mortos, naufragam, perderam-se, nada mais sabemos deles. Pois só regressa a casa quem se encontrou a si próprio no caminho.

Ulisses volta porque quer voltar. No vasto mundo exterior das aventuras, é o corpo da mulher amada que o guia, como força centrípeta, para a interioridade da casa, do leito onde a reencontra, numas segundas núpcias que reactualizam as primeiras. A tensão exterioridade-interioridade é o ritmo subterrâneo da narrativa.

Por amor de uma mulher, mortal como ele, Ulisses recusa a imortalidade oferecida por Calipso, vence o canto das sereias, os poderes 
mágicos de Circe. Regressa a Ítaca, reentra em casa, volta ao papel de rei, de pai, de esposo, e, segundo a profecia de Tirésias, na descida ao lugar dos mortos que também fez parte do seu percurso, terá "uma morte suave" quando chegar a hora.

Assim nos diz a leitura "canónica" da "vulgata" homérica.

No entanto é extremamente interessante verificar que a Antiguidade não considerou esta versão a única possível - e por isso nos deixou outras. Fora da "vulgata" homérica, Paulo e Cecília encontram outras versões, estimulantes porque se abrem a interpretações curiosamente "actuais":

Penélope ouve rumores sobre a morte de Ulisses e corre a afogar-se no mar. Mas é salva por pássaros, provavelmente gaivotas, que a trazem até à praia;

Penélope cansa-se de esperar por Ulisses e cede aos pretendentes, sobretudo a um deles, Anfínomo. Ulisses regressa e mata-a, ao saber-se atraiçoado;

Ulisses não mata Penélope, mas torna a partir de Ítaca, desolado com a sua infidelidade;

Cansada de esperar, Penélope deita-se com os cento e vinte e nove pretendentes. Desses amores nasce o grande deus Pã - uma criatura híbrida, sobre-humana, ligada à força criativa e bela da natureza, mas também infra-humana, animalesca e lasciva;

Ulisses regressa e é morto por seu filho. Não por Telémaco, mas por Telégono, filho de Ulisses e de Circe. Depois de matar Ulisses, Telégono casa com a sua mulher, Penélope, ligando desse modo a Édipo o mito de Ulisses.

A Antiguidade é portanto pródiga em versões do mito, mostrando que a ficção, como a realidade, pode olhar-se de muitas perspectivas. 
No "jogo" de procurar Ulisses, Paulo e Cecília seguem algumas destas pistas: através da sua ausência, Ulisses roubou a vida a Penélope e a Telémaco, que não cresceu e ficou sempre no papel de filho. Ulisses ocupou todo o espaço, passado e futuro. Só ele foi rei.

Mas vinte anos depois já não seria rei por direito próprio, tornar-se-ia o usurpador, o que viria roubar o trono do seu filho. Telémaco deveria ter libertado a mãe dos pretendentes, ser ele próprio rei, ter por sua vez uma mulher e um filho. Ulisses já não teria lugar quando voltasse, a não ser como súbdito do seu filho.

No entanto, na Odisseia Telémaco não faz mais do que ajudar o pai a recuperar o poder para si próprio. Ulisses exige controlar tudo, ser o senhor de tudo, até do tempo.

$\mathrm{Na}$ Odisseia o tempo obedece-lhe. De repente vinte anos não passaram, o leito conjugal e a mulher amada continuam lá, à sua espera, e a deusa Atena faz com que a noite do reencontro não termine antes de Ulisses, através de amor e de palavras, ter de novo ligado os fios quebrados do passado e do presente, como se fosse possível eliminar no meio a ruptura.

Este é o final feliz que já a imaginação da Antiguidade questionava. Tal como hoje nós a questionamos: não há lugar para deuses que suspendam o tempo, o anulem ou prolonguem, à medida do nosso desejo. Não há regresso. Na vida não se pode voltar atrás. Por isso a história não pode ser contada como Homero a contou.

Por outro lado, é possível imaginar que Ulisses encontra na guerra de Tróia não apenas o dever viril de combater, mas também, ou talvez sobretudo, um alibi para deixar Penélope. A mulher, o filho, a ilha de Ítaca tornam-lhe a vida demasiado estreita, está cansado do quotidiano doméstico e anseia por fazer-se ao largo, em busca de aventuras. (Curiosamente, as versões da Antiguidade em que Ulisses se finge louco, para não ter que deixar Ítaca e fazer a guerra, podem ser lidas como tenta- 
tivas de responder, negando-as, a este tipo de objecções). Na verdade Ulisses é o homem de uma só mulher - mas não renuncia a conhecer todas as outras.

Penélope, noutra versão ou versões da Antiguidade, nem sequer foi aliás a sua primeira escolha, mas sim Helena, a mais bela da Grécia. Mas Ulisses acaba por casar com Penélope, prima de Helena. Uma escolha sensata, porque também ela é filha de rei e oportunidade de um casamento economicamente vantajoso. A beleza de Helena é um risco demasiado grande - como a História provou. Helena é um intenso objecto de desejo para os homens, e não é fácil prendê-la no leito conjugal. Por isso Ulisses recua e prefere escolher Penélope, menos desejável porque menos bela. Porque ele quer a segurança do leito e do lar.

No entanto é a ausência do lar que vai preencher a sua vida (na época vinte anos era praticamente o tempo da vida adulta),e os seus encontros decisivos na viagem serão com outras mulheres. Quase todas perigosas, figuras de sedução e de morte: as sereias, que o seduzem pelo canto - pela palavra cantada, pela música da palavra, a ele que é o herói de um canto, de um poema cantado, em que a dada altura ele próprio cantará/contará, na sua voz.

As sereias são suas irmãs no canto, na vertigem do canto, que tudo engloba - elas sabem o que aconteceu no passado, o seu canto é conhecimento e poder.

Ulisses não cede às suas vozes, sabe que elas devoram quem vai ao seu encontro. E consegue (com ajuda divina) escapar aos sortilégios de Circe e aos braços amorosos de Calipso.

Nausícaa, pelo contrário, não representa um perigo. É uma adjuvante, uma jovem núbil que se apaixona no primeiro encontro e em algumas versões Ulisses, decepcionado pela traição de Penélope, voltará para desposar; e noutras versões casará com Telémaco e será rainha de Ítaca um dia. 
Rodeado de mulheres sedutoras que vai sempre abandonando, Ulisses é, na visão de Pierre Solié, um narcísico "filho-amante" que, em todas as suas viagens, busca a sereia impossível que é o seu próprio reflexo4.

Também Paulo busca em Cecília a mulher-todas-as-mulheres. Cecília surgirá como Nausícaa (na história de ambos e no quadro "A manhã de Nausica"), como Penélope, ou Helena.

Tróia (lugar de Helena) existe também, por uma interessante coincidência geográfica, muito perto de Lisboa; apesar de serem romanas as ruínas da antiga povoação, encontraram-se restos arqueológicos de vasos gregos nas proximidades, e o topónimo Tróia, cuja origem se desconhece, estimula a imaginação. É natural portanto que as personagens se divirtam a desenhar na praia de Tróia o roteiro de Ulisses, e imaginem como sendo deste as pegadas que Paulo deixa na areia, e que Cecília fotografa. E é plausível que Paulo, que amou Cecília na praia, pinte depois o quadro "Em Tróia com Helena" e invente um episódio que não encontrou em nenhuma fonte, mas no seu próprio imaginário faz sentido: Ulisses, cuja primeira escolha não foi Penélope, vive em Tróia conquistada e devastada uma hora de amor com Helena. Só depois inicia o seu regresso a casa.

Os papeis de homem e mulher, na Odisseia bem definidos e delimitados, são aqui questionáveis e intermutáveis: é Cecília que parte, e Paulo que a espera, como Penélope, na casa aonde ela não regressa. E onde ele, finalmente, cansado de esperar, queima em imaginação o leito de oliveira onde se deitaram.

E é problemático, e não um dado evidente e adquirido, o papel e o lugar de um filho e o papel e o lugar de um pai, como o papel e o lugar de uma mulher e de uma mãe.

4 Cf. Pierre Solié, La femme essentielle. Mythanalyse de la Grande Mère et de ses fils-amants, Paris, Seghers-Laffont, 1981, p. 421. 
A vida troca depois as voltas a Paulo e Cecília e afasta-os, em histórias pessoais que aparentemente se desligaram do mito de Ulisses. Mas a exposição/instalação que imaginavam acaba por acontecer e, ao mesmo tempo que se mantém fruto da sua imaginação, usa-os também a eles como objecto e como material, forçando-os a exporem-se, quando julgam expor apenas a sua visão de Lisboa. Cecília, cuja viagem pelo mundo foi sobretudo para si própria, encarna, também ela, o papel de Ulisses: também ela regressa, e é ela que tem pronta a exposição que Paula hesita em levar a cabo.

É aliás ao realizar a exposição de Cecília que Paulo verdadeiramente a reencontra. E ao mesmo tempo a perde, como Orfeu a Eurídice. Porque na vida não há regresso, nem voltar atrás.

No entanto o romance escolhe reactualizar o final feliz da Odisseia. Penélope, contudo, já não é Cecília, mas Sara. Paulo libertou-se de Cecília e deixou-a partir, dentro de si, do seu imaginário onde ela se tinha instalado (a instalação/exposição tem mais do que um sentido. Ou é ainda Cecília que Paulo reencontra em Sara?)

Nada é linear, através dos milénios as relações humanas permanecem complexas e questionáveis. Entre homens e mulheres, como entre países e civilizações.

Paulo termina a exposição em 2010, altura em que se tornou mais patente a incerteza da aventura europeia e a crise de valores do mundo. As histórias individuais das personagens e a História recente do país entrelaçam-se ao longo do romance, a realidade e o tempo surgem em contraponto com a dimensão intemporal do mito.

A viagem à Grécia dos jovens amantes sublinha a feição mediterrânica dos países do sul e assinala os nossos pontos de contacto, apesar da geografia atlântica de Portugal. É em países do norte da Europa que as personagens acabam por viver a maior parte das suas vidas, em histó- 
rias pessoais que aparentemente nada têm a ver com os anos passados em Lisboa. No entanto é aqui que se reencontram, e que a exposição/ instalação tem lugar, reactualizando o projecto da sua juventude: um projecto que a História, passada e presente, sempre inquietou e abriu a interrogações, que no momento presente se agudizam:

Quem somos, e para onde caminhamos? Como ignorar ou esquecer (como alguns pretendem) que a Grécia foi - é - o berço da Europa, que a Europa não pode caminhar sem ela? E quem somos e para onde vamos, a nível global, enquanto seres humanos? Onde é o lugar a que chamamos casa?

Alguma vez a Terra será o abrigo natural daqueles que a habitam? Ou mantém-se um lugar de luta de exploradores e de explorados, de impérios que caem e renascem, andamos à deriva, num mar revolto, na jangada de Ulisses, e nunca chegaremos a bom porto?

Iremos finalmente interiorizar e alguma vez pôr em prática valores (posteriores a Homero, mas, não esqueçamos: gregos) como a Racionalidade e a Democracia?

Quem sair da exposição/instalação ou fechar a última página do livro não terá certamente respostas. Mas talvez entreveja a urgência de (re)pensar o mundo. E lhe ocorra que, contra a permanente ameaça da barbárie, não temos senão o antídoto da alma: das humanidades, da arte, do amor e dos afectos, da liberdade, da justiça, da cultura. 